\title{
Three-dimensional treatment outcomes in Class II patients treated with the Herbst appliance: A pilot study
}

\author{
Megan LeCornu $^{\mathrm{a}}$, Lucia H. S. Cevidanes ${ }^{\mathrm{b}}$, Hongtu Zhu ${ }^{\mathrm{c}}$, Chih-Da Wu ${ }^{\mathrm{d}}$, Brent Larson ${ }^{\mathrm{e}}$, and \\ Tung Nguyen ${ }^{\dagger}$ \\ aprivate practice, Santa Clarita, Calif \\ ${ }^{\mathrm{b}}$ Assistant professor, Department Orthodontics and Pediatric Dentistry, University of Michigan, \\ Ann Arbor, Mich \\ cProfessor, Department of Biostatistics, Gilling School of Global Public Health, University of North \\ Carolina, Chapel Hill, NC \\ dPhD student, Department of Biostatistics, Gilling School of Global Public Health, University of \\ North Carolina, Chapel Hill, NC

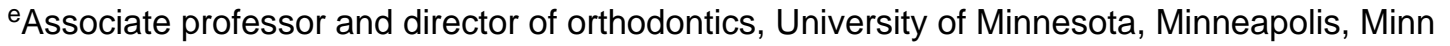 \\ ${ }^{\mathrm{f} A s s i s t a n t}$ professor, Department of Orthodontics, University of North Carolina, Chapel Hill, NC
}

\section{Abstract}

Introduction-The aims of this study were to analyze 3-dimensional skeletal changes in subjects with Class II malocclusion treated with the Herbst appliance and to compare these changes with treated Class II controls using 3-dimensional superimposition techniques.

\begin{abstract}
Methods-Seven consecutive Herbst patients and 7 Class II controls treated with Class II elastics who met the inclusion criteria had cone-beam computed tomographs taken before treatment, and either after Herbst removal or at posttreatment for the control subjects. Three-dimensional models were generated from the cone-beam computed tomography images, registered on the anterior cranial bases, and analyzed using color maps and point-to-point measurements.
\end{abstract}

Results-The Herbst patients demonstrated anterior translation of the glenoid fossae and condyles (right anterior fossa, $1.69 \pm 0.62 \mathrm{~mm}$; left anterior fossa, $1.43 \pm 0.71 \mathrm{~mm}$; right anterior condyle, $1.20 \pm 0.41 \mathrm{~mm}$; left anterior condyle, $1.29 \pm 0.57 \mathrm{~mm}$ ), whereas posterior displacement predominated in the controls (right anterior fossa, $-1.51 \pm 0.68 \mathrm{~mm}$; left anterior fossa, $-1.31 \pm$ $0.61 \mathrm{~mm}$; right anterior condyle, $-1.20 \pm 0.41 \mathrm{~mm}$; left anterior condyle, $-1.29 \pm 0.57 \mathrm{~mm} ; P$ $<0.001)$. There was more anterior projection of B-point in the Herbst patients $(2.62 \pm 1.08 \mathrm{~mm}$ vs $1.49 \pm 0.79 \mathrm{~mm} ; P<0.05)$. Anterior displacement of A-point was more predominant in the controls when compared with the Herbst patients $(1.20 \pm 0.53 \mathrm{~mm}$ vs $-1.22 \pm 0.43 \mathrm{~mm} ; P$ $<0.001)$.

Copyright $(9) 2013$ by the American Association of Orthodontists.

Address correspondence to: Tung Nguyen, Department of Orthodontics, UNC School of Dentistry, CB\#7450, Chapel Hill, NC 27599-7450; nguyetun@unc.edu.

All authors have completed and submitted the ICMJE Form for Disclosure of Potential Conflicts of Interest, and none were reported. 
Conclusions-Class II patients treated with the Herbst appliance demonstrated anterior displacement of the condyles and glenoid fossae along with maxillary restraint when compared with the treated Class II controls; this might result in more anterior mandibular projection.

Treatment of Class II malocclusions is a common challenge for orthodontists in the United States. Approximately one third of all patients have a Class II Division 1 malocclusion. ${ }^{1,2}$ Mandibular retrognathism is the primary etiologic factor in most of those patients. ${ }^{3,4}$ Functional appliances have been shown to be effective in correcting Class II malocclusions by decreasing overjet and achieving Angle Class I canine and molar relationships. ${ }^{3-7}$ Eliminating patient compliance factors and delivering continuous forces give fixed functional appliances a distinct treatment advantage compared with removable appliances. Many studies have reported the greatest anteroposterior improvements in mandibular projection when using fixed Herbst functional appliances. ${ }^{3,4,7-12}$

Functional appliances, such as the Herbst, have been purported to improve mandibular projection, consequently improving the underlying skeletal discrepancies. ${ }^{7,8,10,13}$ However, the available data that examine the extent of skeletal vs dentoalveolar adaptation in Class II correction with functional appliances are controversial. ${ }^{5,6,13,14}$ The skeletal component of Class II correction has been reported to be from 13\% to 85\%.5,11,14-21 Variations in reported skeletal changes are due to a number of factors ranging from physiologic and anatomic inconsistencies in the study subjects to limitations in the study methodologies.

Studies focusing on patients treated using the Herbst appliance during the peak of pubertal growth exhibit vast inconsistencies in the extent of skeletal vs dentoalveolar adaptation. ${ }^{3,8,13,17,22-24}$ The differences in treatment timing alone do not account for the ambiguities reported in the literature. Studies suggest that anatomic factors, such as facial type and gonial angle, might have an impact on the extent of skeletal adaptation. ${ }^{3,11,17,22}$ However, literature focusing on these factors is limited. Ultimately, it is impossible to accurately assess the extent of skeletal adaptation, let alone examine how anatomic factors affect these adaptations, with the limitations of current methodologies.

Although it has been suggested that translation of the glenoid fossa/condyle complex is the source of skeletal adaptation, previous studies have used condylion or a proxy point for condylion to make these assessments. ${ }^{6,15,23-26}$ Poor reliability of identifying this landmark brings to question the accuracy of the findings in these studies. ${ }^{27}$ Excitement regarding the possibility of glenoid fossa remodeling using functional jaw orthopedic appliances arises from the findings in animal studies. ${ }^{28-34}$ However, these findings have yet to be definitively extended to human subjects. Even though studies report improved mandibular projection with Herbst treatment, the factors leading to these changes are elusive because of limitations in 2-dimensional (2D) cephalometric imaging.

Two-dimensional imaging is subject to magnification, distortion, and patient positioning errors, and obstruction of critical landmarks by overlapping anatomic structures.

Additionally, there is inherent examiner bias in the registration process if the examiners are not blinded. Shortcomings of 2D linear and angular cephalometric measurements do not explain the complex 3-dimensional (3D) process of bone remodeling over time and can also 
account for discord in the literature regarding the skeletal effects of Herbst therapy. Threedimensional imaging and superimposition techniques overcome these inadequacies by accurately examining and measuring maxillary and mandibular adaptive and positional changes relative to the anterior cranial base. ${ }^{35-37}$ The 3D superimposition protocol uses a ridged voxel-based registration technique that eliminates examiner bias in the registration process.

Whereas the Herbst appliance is effective in correcting Class II malocclusions by decreasing overjet and correcting to an Angle Class I molar relationship, the extent of skeletal vs dentoalveolar changes producing these effects is controversial and of great interest to the orthodontist. The aims of this study were to use 3D imaging and superimposition techniques to report skeletal changes associated with Class II correction in Herbst patients, and to compare these findings with matched Class II patients treated with elastics. Specifically, maxillary positional changes, differences in mandibular growth, and condylar and glenoid fossa positional changes were evaluated.

\section{MATERIAL AND METHODS}

Adolescent patients near the pubertal growth spurt (determined by cervical vertebral maturation method stages 3 and 4 ) with Class II skeletal relationships (ANB, $\geq^{\circ}$ ) and Class II molar relationships seen at the University of North Carolina Department of Orthodontics were evaluated for Herbst appliance therapy. ${ }^{38}$ Seven consecutive patients who met the inclusion criteria were enrolled in this prospective pilot study (Table I). Seven Class II control subjects treated with Class II elastics were obtained from the University of Minnesota database. Approvals from the University of North Carolina and the University of Minnesota institutional review boards were obtained for this study.

The Herbst appliance design included miniscope telescoping arms with a cantilever from the mandibular first molars and occlusal rests on the second molars and the first premolars (Allesee Orthodontic Appliances, Sturtevant, Wis). The appliance was initially advanced to a Class I molar position. Fixed appliances were placed on the maxillary and mandibular incisors and canines and tied back to the molar crown after alignment was achieved. The Herbst appliance was advanced at 2-mm increments to an overcorrected position (overjet, 0 to $-1 \mathrm{~mm}$ ). The duration of advancement was 6 to 9 months with a 3- to 4-month retention period thereafter. It has been suggested that an extended retention period allows for adequate bone maturation and thus might lead to a more stable result. ${ }^{39}$ The average treatment time was $11.42 \pm 1.4$ months for the Herbst subjects in this study; this was longer than the usual 6- to 8-month treatment durations of other authors. $3,14,17,40$

Cone-beam computed tomography (CBCT) scans were taken before treatment (T1) for both the Herbst and the control patients and immediately after removal of the Herbst appliance (T2) and after treatment for the control patients (T2). The premolars and molars were bonded on all Herbst patients to complete treatment, and CBCT scans were taken after appliance placement. The Herbst patients' scans were taken using the New Tom 3G (Aperio Services, Sarasota, Fla) with a 12-in field of view. The control subjects' CBCT scans were taken with an i-Cat machine (Imaging Sciences International, Hatfield, Pa) with a $16 \times 22$ 
$\mathrm{cm}$ field of view. All patients (control and Herbst) were instructed to bite into maximum intercuspation during scan capture. T1 and T2 scans for both groups were evaluated to make sure that the condyles were seated in the center of the fossa. Patients were excluded from the study if the condyles were postured in either the T1 or T2 scans. The DICOM scans were downsized to $0.5 \times 0.5 \times 0.5 \mathrm{~mm}$ and deidentified using Imagine (http:// www.ia.unc.edu/dev/download/imagine/index.htm). The scans were down-sized to decrease the computational power and time required to compute cranial based registration. Waltrick et $\mathrm{al}^{41}$ recently evaluated CBCT accuracy when the voxel size of the scan was changed from $0.2 \mathrm{~mm}$ to $0.3 \mathrm{~mm}$ to $0.4 \mathrm{~mm}$ and concluded that there was no statistical difference in error measurements between the different voxel sizes. ITK SNAP (www.itksnap.org) was used to construct virtual 3D surface models. ${ }^{35}$ Scans at $\mathrm{T} 1$ and $\mathrm{T} 2$ were registered on the anterior cranial fossa using a fully automated voxel-wise ridged registration technique described by Cevidanes et al. ${ }^{35-37}$ This process uses voxel intensity and shape of the region of interest for the registration. Boundaries for the anterior cranial base registration were defined anteriorly by the inner cortical layer of the frontal bone, posteriorly by the anterior wall of the sella, laterally including the lesser wings of the sphenoid bone, and superiorly including the frontal bone. This region includes the cribriform plate and the superior aspect of the ethmoid bone. These structures are known to complete growth by the age of 7 years and are thus considered stable landmarks. ${ }^{42-44}$

Registered 3D models were then analyzed using Vectra Analysis Model software (Canfield Imaging Systems, Fairfield, NJ). Quantitative evaluations of growth and treatment response were calculated using (1) an iterative closest point method with color map tools and (2) point-to-point landmark identification. Landmarks selected for this study are shown in Figure 1. Additional landmarks included $\mathrm{Co}^{\prime}$ and $\mathrm{Go}^{\prime} . \mathrm{Co}^{\prime}$ is defined by the most superoposterior point of the posterior condylar head identified from the sagittal view. Go' is defined as the most posterior aspect of the mandibular corpus at the point where it starts to curve from the angle of the mandible, identified from a sagittal view with the functional occlusal plane parallel to the floor. For all measurements, positive values indicated anterior displacements and negative values indicated posterior displacements relative to T1. Cephalometric landmark placement on 3D volumes has been shown to be accurate and reproducible. ${ }^{45,46}$

\section{Statistical analysis}

Data analysis was conducted using the SPSS statistical software package (version 12.0; SPSS, Chicago, Ill). Means, standard deviations, and ranges were calculated for the Herbst and control subjects to describe their skeletal and dental characteristics. Statistical differences were assessed using analysis of variance. The Wilcoxon signed-rank test was used to assess differences in displacement between the Herbst and the control subjects.

Repeated measurements were made after 1 week by an examiner (M.L.), and intraexaminer correlation coefficients (ICC) were used to evaluate the reliability of repeated measures. A 1 -sample $t$ test was performed on duplicate measurements to test for systematic errors. 


\section{RESULTS}

Descriptive statistics for the Herbst and control patients are summarized in Table I. The patients were well matched with regard to age, ANB (Herbst, 5.29 ${ }^{\circ}$; controls, $6.10^{\circ}$ ), and incisor angulations. The control subjects had a longer observation time of $18.42 \pm 3.05$ months compared with $13 \pm 0.577$ months for the Herbst subjects $(P=0.003)$ and a larger A-N perpendicular measurement $(P=0.04)$. Additionally, the Herbst subjects had a flatter mandibular plane angle with a mean of $25.73^{\circ} \pm 6.13^{\circ}$ compared with $36.71^{\circ} \pm 2.82^{\circ}$ in the controls $(P=0.001)$.

Qualitative assessment of maxillary skeletal changes was conducted using a semitransparent overlay of the superimpositions and an iterative closest point measurement from color maps (Figs 2 and 3). For structures that were obstructed from view, a mesh transparency for T2 allowed for better visualization of the superimpositions. All Herbst patients, except for 1 subject, demonstrated maxillary restraint (Fig 2). Four Herbst subjects displayed the largest maxillary displacements. Retroclination of the maxillary incisors was evident in 2 control subjects, and maxillary restraint was noted only in 1 control subject (Fig 3).

Quantitative assessment of maxillary changes is reported in Table II and Figure 4. Greater anterior projections of A-point and ANS (1.2 and $1.96 \mathrm{~mm}$, respectively) were shown by the treated controls, when compared with the Herbst subjects $(-1.22$ and $0.26 \mathrm{~mm}$, respectively; $P<0.01)$.

Skeletal changes in the mandible are reported in Table II and Figures 5 and 6. B-point had average displacements of $2.62 \mathrm{~mm}$ in the Herbst subjects and $1.49 \mathrm{~mm}$ in the control subjects, showing a statistically significant increase in the anterior projection of B-point in the Herbst patients by $1.14 \mathrm{~mm}(P=0.05)$. Additionally, a $2.23-\mathrm{mm}$ difference was noted for $\mathrm{Go}^{\prime}$-Co right $(P=0.02)$. All other linear mandibular changes were not statistically significant when comparing the Herbst and the control subjects (Table II, Fig 5). In addition, angular measurements evaluating opening of the gonial angle and condylar flexure showed no statistical differences between the Herbst and the control subjects (Table II, Fig 6).

Mean condylar and glenoid fossa displacements are shown in Table II and Figures 7 and 8. In general, the Herbst patients showed forward displacement of the condyles, whereas the control subjects had posterior displacement. The mean differences in displacement of the condyles between the 2 groups were approximately 2.5 to $2.9 \mathrm{~mm}$ when measured from the anterior surface $(P<0.001)$ and 1.74 to $1.35 \mathrm{~mm}$ when measured from the posterior surface of the condyles $(P<0.05)$.

In addition, point-to-point linear changes were evaluated for condylion (Table II, Fig 8). Box plots in Figure 8 depict the net anterior displacement of condylion in the Herbst patients (right, $0.38 \mathrm{~mm}$; left, $0.56 \mathrm{~mm}$ ). Conversely, a net posterior displacement of condylion was observed in the control group (right, $-0.88 \mathrm{~mm}$; left, $-1.16 \mathrm{~mm}$ ). These changes in condylar position were less than those found using the iterative closest point method (right, $1.26 \mathrm{~mm}$; left, $1.72 \mathrm{~mm})$ but were statistically significant $(P>0.01)$. 
Mean changes for fossa remodeling are shown in Table II and Figure 8. The Herbst patients showed resorption at the anterior wall (right, $1.69 \mathrm{~mm}$; left, $1.43 \mathrm{~mm}$ ) with deposition at the posterior wall of the glenoid fossa (right, $0.59 \mathrm{~mm}$; left, $0.79 \mathrm{~mm}$ ) (Figs 7 and 8).

Conversely, the control group showed bony apposition on the anterior wall (right, -1.51 $\mathrm{mm}$; left, $-1.31 \mathrm{~mm}$ ) with resorption at the posterior wall (right, $-1.24 \mathrm{~mm}$; left, $-1.41 \mathrm{~mm}$ ). This corresponds with the direction of condylar displacement in the groups (Fig 8).

Figure 9 shows the composite of the individual color maps, demonstrating the global changes computed with the iterative closest point algorithms. Although the maxillary, mandibular, condylar, and glenoid fossa positional changes in the Herbst patients showed statistical differences compared with the control subjects, considerable variations in magnitude and direction of these skeletal changes were seen when examining the color maps of each subject (Fig 9).

ICC values and 95\% confidence intervals of the ICC for each linear and angular measurement are reported in Table III. All variables had ICC values greater than 0.90, showing high levels of reliability. A 1-sample $t$ test showed no significant differences between the repeated measurements and small within-subject errors relative to betweensubject variability, indicating no systematic bias.

\section{DISCUSSION}

Previous studies examining functional appliances often used samples from the Bolton-Brush or Michigan growth studies for their untreated Class II controls. ${ }^{13,15,47}$ Unfortunately, no such 3D sample exists today. An ethical issue regarding not treating patients with a Class II malocclusion during the pubertal growth spurt and the time associated with the optimal treatment response for Class II correction prevent us from obtaining 3D scans from untreated Class II patients to serve as controls. Class II elastics have been shown to act primarily through dentoalveolar movements with no skeletal enhancement. ${ }^{20}$ Nelson et al ${ }^{20}$ reported that the skeletal contribution to reduction in overjet was only $4 \%$ in the control subjects compared with $51 \%$ in the Herbst subjects. Therefore, using Class II subjects treated solely with Class II elastics as control subjects to evaluate skeletal and orthopedic changes can be justified.

The aims of this study were to evaluate the maxillary positional changes in the Herbst subjects and to compare these changes with the controls. Numerous studies have reported a maxillary restraining effect, comparable with headgear, produced by Herbst treatment. $3,14,15,26,47,48$ Interestingly, other studies have suggested that the skeletal headgear effect of the Herbst is negligible. ${ }^{5,20,22}$ When considering the variances in the literature, it is important to understand the various methodologies used to measure changes in A-point. The method developed by Pancherz ${ }^{17}$ uses a reference grid constructed from the occlusal line and the occlusal line perpendicular. Maxillary measurements with this method are subject to patient-positioning errors. The authors of many studies use SNA to examine maxillary changes. ${ }^{3,16,26}$ However, increases in the vertical dimension as seen with growth will mask the anteroposterior changes when using these angular measurements. ${ }^{8}$ Skeletal changes observed at A-point undeniably depend on the methodology used. Our 3D study showed the 
expected forward and downward growth pattern of the maxilla in most of our Class II control subjects. However, the Herbst group showed a mild maxillary restraining effect.

Alteration of anteroposterior projection of the mandible can be attributed to (1) changes in mandibular growth, (2) changes in the direction of growth, or (3) condylar/fossa positional changes. Previous studies reported conflicting results, with some showing increased mandibular length with Herbst treatment, $3,8,14,15,17,22,26,47,48$ whereas other studies showed no significant increase in mandibular length. ${ }^{5,21}$ Deviations in patient positioning, as well as superimpositions between the left and right sides of the mandible, can affect the $2 \mathrm{D}$ measurements of mandibular corpus length and ramus height. In addition, the conflicting findings regarding mandibular length were addressed by Voudouris et al, ${ }^{33,34}$ who noted that in preadolescent cynomolgus monkeys (Macaca fasicularis), the condylar growth response was increased with Herbst treatment, but in adolescent animals there was no increase in the thickness of the prechondroblastic or chondroblastic zones and thus no increase in condylar growth. They suggested that the adaptive capability of adolescent monkeys and possibly adolescent humans might be chiefly limited to the glenoid fossa with little potential for increased condylar length. Perhaps skeletal maturity could have a greater and more direct influence on the skeletal response to the Herbst appliance than we previously understood. Although our findings suggest no statistically significant difference for mandibular length between the Herbst and control groups, there was a difference in observation times for these groups. The control group had an additional 5 months of observation time, which would increase the perceived mandibular growth (Co-Gn)when compared with the Herbst subjects.

In additional to growth, mandibular directional growth changes impact anteroposterior projection of the mandibular base. Animal studies have shown mild opening of the gonial angle with mandibular advancement, ${ }^{33,34}$ and some human studies have made similar conclusions. ${ }^{14,17}$ Our study and others showed no differences in gonial angle or condylar flexure between the Herbst and the control subjects. ${ }^{3,11,26}$ The Herbst subjects in our study had lower mandibular plane angles. A previous study by Pancherz and Michailidou ${ }^{9}$ examined skeletal changes in hyperdivergent and hypodivergent facial types. They found that hyperdivergent subjects had more posteriorly directed condylar growth compared with hypodivergent subjects. Posteriorly directed condylar growth would lead to opening of the gonial angle and increased condylar flexure. The larger number of hypodivergent subjects in this study might have affected our results on gonial angle and condylar flexure changes.

Translation of the glenoid fossa has been shown to contribute to mandibular positional changes after Herbst treatment in animal studies. ${ }^{28,29,33,34,49}$ However, 2D imaging techniques used in human studies can have errors when assessing remodeling of the glenoid fossa. Human studies often rely on an unchanged condyle-fossa relationship because they use the method described by Buschang and Santos-Pinto ${ }^{50}$ Furthermore, these authors used condylion or articulare as a proxy point to approximate the position of the fossa. ${ }^{9}$ Ruf and Pancherz ${ }^{24}$ conducted a magnetic resonance imaging study to evaluate effective condylar growth in Herbst patients. They noted increased uptake in the T2-weighted sequences in the glenoid fossa and condyle. These were interpreted to be definitive areas of condyle and fossa remodeling. However, because the incidence of capsulitis rises during Herbst treatment up 
to $100 \%$, virtually all patients would be expected to have increased $\mathrm{T} 2$ signals because of the amplified inflammatory process. ${ }^{51,52}$ Differentiating inflammatory processes from the cellular cascade of skeletal remodeling is difficult. In addition, magnetic resonance images lack detailed information regarding bony structures and might not be the best tool to evaluate fossa remodeling. With 3D CBCT scans and current registration and superimposition techniques, we were able to accurately analyze skeletal changes at the glenoid fossa (Fig 7). We found resorption of the anterior wall of the glenoid fossa with deposition at the posterior wall in the Herbst patients. This is in direct contrast to findings in the control subjects who had posteriorly directed remodeling of the fossa. The posterior repositioning of the glenoid fossa we observed in the control group has been well documented in Class II subjects and represents the expected Class II growth pattern. ${ }^{41,50,53-56}$

Our findings suggest that the Herbst appliance alters the growth pattern of the glenoid fossa, resulting in a more anteriorly positioned fossa and therefore a more anteriorly position mandible.

There is concern regarding changing condylar position in the glenoid fossa with anterior repositioning appliances such as the Herbst. However, if the condylar and fossa positions are compared in Figures 7 and 8, it is evident that their displacements are occurring in unison. This supports conclusions in both animal and human studies suggesting that the condyleglenoid fossa relationship remains relatively unchanged with Herbst treatment. ${ }^{24,30,57}$ This is the first 3D study to clearly demonstrate anterior repositioning of the fossa and condyle in response to Class II functional appliance therapy in humans.

This study was designed as a pilot project to determine whether skeletal differences between Herbst subjects and patients treated with Class II elastics could be measured. As a pilot study, limitations in the sample size are inherent. Additional weaknesses of this study sample arise from differences in observation times between the Herbst subjects and the control patients, and the initial mandibular plane angle. This confounder has an effect on the statistical comparison for treatment differences. Since the control group had an average observation time 5 months longer, those subjects were expected to have greater anteroposterior changes from normal growth. Most likely, this difference might underestimate the skeletal anteroposterior changes resulting from Herbst treatment. Furthermore, the difference in the initial mandibular plane angle might influence skeletal growth of the mandible corpus. However, Pancherz and Michailidou ${ }^{9}$ reported that differences in anteroposterior displacement of the fossa between hyperdivergent, normal, and hypodivergent groups were less than $0.2 \mathrm{~mm}$, and vertical displacements were less than $0.6 \mathrm{~mm}$; these are significantly less than our observed changes of the fossa. A larger study that can further evaluate the skeletal changes we observed for these patients with a longterm follow-up is recommended.

The relapse potential for patients treated with the Herbst appliance is well documented; however, the mechanism for relapse is not well understood. ${ }^{7,18,20,31,57-59}$ An animal study suggested that the remodeling process allowing adequate bone maturation from type III to type I collagen might require an increased retention phase. ${ }^{39}$ The Herbst patients in this 
study had longer treatments to promote mature bone formation during the remodeling process. It will be interesting to see whether the skeletal adaptations in the glenoid fossa will be retained. Clearly, follow-up studies with 3D imaging techniques to address the true nature of the relapse in the Herbst subjects are indicated.

\section{CONCLUSIONS}

Three-dimensional imaging and superimposition techniques showed the following skeletal adaptations.

1. Herbst treatment produced anterior displacement of the condyles with adaptive forward remodeling of the glenoid fossa whereas the Class II controls exhibited distal displacement of the temporomandibular joint complex.

2. The Herbst group showed maxillary growth restraint compared with the controls.

3. No significant differences in mandibular corpus and ramal growth, condylar flexure, or gonial angle change were observed between the 2 groups.

4. Considerable variations in treatment response were observed in both groups. Larger sample sizes are needed to verify these findings.

\section{Acknowledgments}

We thank Hsiao-Han (Sharon) Chen and John Paul Zermeno for their time and dedication to this study because their efforts were crucial for its completion. We also acknowledge the American Association of Orthodontists Foundation, Southern Association of Orthodontists, and National Institute of Dental and Craniofacial Research for their support.

\section{References}

1. Proffit WR, Fields HW Jr, Moray LJ. Prevalence of malocclusion and orthodontic treatment need in the United States: estimates from the NHANES III survey. Int J Adult Orthod Orthognath Surg. 1998; 13:97-106.

2. McNamara JA Jr. Components of Class II malocclusion in children 8-10 years of age. Angle Orthod. 1981; 51:177-202. [PubMed: 7023290]

3. Baccetti T, Franchi L, Stahl F. Comparison of 2 comprehensive Class II treatment protocols including the bonded Herbst and headgear appliances: a double-blind study of consecutively treated patients at puberty. Am J Orthod Dentofacial Orthop. 2009; 135:698, e1-10. [PubMed: 19524823]

4. Shen G, Hägg U, Darendeliler M. Skeletal effects of bite jumping therapy on the mandibleremovable vs. fixed functional appliances. Orthod Craniofac Res. 2005; 8:2-10. [PubMed: 15667639]

5. Barnett GA, Higgins DW, Major PW, Flores-Mir C. Immediate skeletal and dentoalveolar effects of the crown- or banded type Herbst appliance on Class II division 1 malocclusion. Angle Orthod. 2008; 78:361-9. [PubMed: 18251608]

6. Baltromejus S, Ruf S, Pancherz H. Effective temporomandibular joint growth and chin position changes: activator versus Herbst treatment. A cephalometric roentgenographic study. Eur J Orthod. 2002; 24:627-37. [PubMed: 12512780]

7. Siara-Olds NJ, Pangrazio-Kulbersh V, Berger J, Bayirli B. Long-term dentoskeletal changes with the bionator, Herbst, twin Block, and MARA functional appliances. Angle Orthod. 2010; 80:18-29. [PubMed: 19852635]

8. Cozza P, Baccetti T, Franchi L, De Toffol L, McNamara JA Jr. Mandibular changes produced by functional appliances in Class II malocclusion: a systematic review. Am J Orthod Dentofacial Orthop. 2006; 129:599, e1-12. [PubMed: 16679196] 
9. Pancherz H, Michailidou C. Temporomandibular joint growth changes in hyperdivergent and hypodivergent Herbst subjects. A long-term roentgenographic cephalometric study. Am J Orthod Dentofacial Orthop. 2004; 126:153-61. [PubMed: 15316469]

10. Obijou C, Pancherz H. Herbst appliance treatment of Class II, Division 2 malocclusions. Am J Orthod Dentofacial Orthop. 1997; 112:287-91. [PubMed: 9294358]

11. Bock N, Pancherz H. Herbst treatment of Class II division 1 malocclusions in retrognathic and prognathic facial types. Angle Orthod. 2006; 76:930-41. [PubMed: 17090166]

12. Lai M, McNamara JA Jr. An evaluation of two-phase treatment with the Herbst appliance and preadjusted edgewise therapy. Semin Orthod. 1998; 4:46-58. [PubMed: 9573874]

13. Serbesis-Tsarudis C, Pancherz H. "Effective" TMJ and chin position changes in Class II treatment. Angle Orthod. 2008; 78:813-8. [PubMed: 18298212]

14. Pancherz H. The effects, limitations, and long-term dentofacial adaptations to treatment with the Herbst appliance. Semin Orthod. 1997; 3:232-43. [PubMed: 9573885]

15. VanLaecken R, Martin CA, Dischinger T, Razmus T, Ngan P. Treatment effects of the edgewise Herbst appliance: a cephalometric and tomographic investigation. Am J Orthod Dentofacial Orthop. 2006; 130:582-93. [PubMed: 17110255]

16. Ruf S, Pancherz H. Herbst/multibracket appliance treatment of Class II division 1 malocclusions in early and late adulthood. A prospective cephalometric study of consecutively treated subjects. Eur J Orthod. 2006; 28:352-60. [PubMed: 16644850]

17. Pancherz H. The mechanism of Class II correction in Herbst appliance treatment. A cephalometric investigation. Am J Orthod. 1982; 82:104-13. [PubMed: 6961781]

18. Pancherz H. The nature of Class II relapse after Herbst appliance treatment: a cephalometric longterm investigation. Am J Orthod Dentofacial Orthop. 1991; 100:220-33. [PubMed: 1877546]

19. Pancherz H, Anehus-Pancherz M. The headgear effect of the Herbst appliance: a cephalometric long-term study. Am J Orthod Dentofacial Orthop. 1993; 103:510-20. [PubMed: 8506812]

20. Nelson B, Hansen K, Hägg U. Class II correction in patients treated with Class II elastics and with fixed functional appliances: a comparative study. Am J Orthod Dentofacial Orthop. 2000; 118:142-9. [PubMed: 10935954]

21. Burkhardt DR, McNamara JA Jr, Baccetti T. Maxillary molar distalization or mandibular enhancement: a cephalometric comparison of comprehensive orthodontic treatment including the pendulum and the Herbst appliances. Am J Orthod Dentofacial Orthop. 2003; 123:108-16. [PubMed: 12594414]

22. Ruf S, Pancherz H. Dentoskeletal effects and facial profile changes in young adults treated with the Herbst appliance. Angle Orthod. 1999; 69:239-46. [PubMed: 10371429]

23. Pancherz H, Fischer S. Amount and direction of temporomandibular joint growth changes in Herbst treatment: a cephalometric long-term investigation. Angle Orthod. 2003; 73:493-501. [PubMed: 14580015]

24. Ruf S, Pancherz H. Temporomandibular joint growth adaptation in Herbst treatment: a prospective magnetic resonance imaging and cephalometric roentgenographic study. Eur J Orthod. 1998; 20:375-88. [PubMed: 9753819]

25. Pancherez H. History, background and development of the Herbst appliance. Semin Orthod. 2003; 9:3-11.

26. Manfredi C, Cimino R, Trani A, Pancherz H. Skeletal changes of Herbst appliance therapy investigated with more conventional cephalometrics and European norms. Angle Orthod. 2001; 71:170-6. [PubMed: 11407768]

27. Adenwalla ST, Kronman JH, Attarzadeh F. Porion and condyle as cephalometric landmarks—an error study. Am J Orthod Dentofacial Orthop. 1988; 94:411-5. [PubMed: 3189243]

28. McNamara JA Jr, Carlson DS. Quantitative analysis of temporomandibular joint adaptations to protrusive function. Am J Orthod. 1979; 76:593-611. [PubMed: 117715]

29. Rabie ABM, Zhao Z, Shen G, Hägg EU, Robinson W. Osteogenesis in the glenoid fossa in response to mandibular advancement. Am J Orthod Dentofacial Orthop. 2001; 119:390-400. [PubMed: 11298312]

30. Woodside DG, Metaxas A, Altuna G. The influence of functional appliance therapy on glenoid fossa remodeling. Am J Orthod Dentofacial Orthop. 1987; 92:181-98. [PubMed: 3477085] 
31. McNamara JA Jr, Bryan FA. Long-term mandibular adaptations to protrusive function: an experimental study in Macaca mulatta. Am J Orthod Dentofacial Orthop. 1987; 92:98-108. [PubMed: 3475974]

32. Hinton RJ, McNamara JA Jr. Effect of age on the adaptive response of the adult temporomandibular joint. A study of induced protrusion in Macaca mulatta. Angle Orthod. 1984; 54:154-62. [PubMed: 6588771]

33. Voudouris JC, Woodside DG, Altuna G, Kuftinec MM, Angelopoulos G, Bourque PJ. Condylefossa modifications and muscle interactions during Herbst treatment, part 1. New technological methods. Am J Orthod Dentofacial Orthop. 2003; 123:604-13. [PubMed: 12806337]

34. Voudouris JC, Woodside DG, Altuna G, Angelopoulos G, Bourque PJ, Lacouture CY, et al. Condyle-fossa modifications and muscle interactions during Herbst treatment, part 2. Results and conclusions. Am J Orthod Dentofacial Orthop. 2003; 124:13-29. [PubMed: 12867894]

35. Cevidanes LHC, Heymann G, Cornelis MA, DeClerck HJ, Tulloch JFC. Superimposition of 3dimensional cone-beam computed tomography models of growing patients. Am J Orthod Dentofacial Orthop. 2009; 136:94-9. [PubMed: 19577154]

36. Cevidanes LHC, Oliveira AEF, Grauer D, Styner M, Proffit WR. Clinical application of 3D imaging for assessment of treatment outcomes. Semin Orthod. 2011; 17:72-80. [PubMed: 21516170]

37. Cevidanes LHS, Styner MA, Proffit WR. Image analysis and superimposition of 3-dimensional cone-beam computed tomography models. Am J Orthod Dentofacial Orthop. 2006; 129:611-8. [PubMed: 16679201]

38. Baccetti T, Franchi L, McNamara JA Jr. An improved version of the cervical vertebral maturation (CVM) method for the assessment of mandibular growth. Angle Orthod. 2002; 72:316-23. [PubMed: 12169031]

39. Chayanupatkul A, Rabie AB, Hägg U. Temporomandibular response to early and late removal of bite-jumping devices. Eur J Orthod. 2003; 25:465-70. [PubMed: 14609014]

40. von Bremen J, Pancherz H. Efficiency of early and late Class II Division 1 treatment. Am J Orthod Dentofacial Orthop. 2002; 121:31-7. [PubMed: 11786869]

41. Waltrick KB, Nunes de Abreu MJ Junior, Correa M, Zastrow MD, Dutra VD. Accuracy of linear measurements and visibility of the mandibular canal of cone-beam computed tomography images with different voxel sizes: an in vitro study. J Periodontol. 2013; 84:68-77. [PubMed: 22390549]

42. Ford E. Growth of the human cranial base. Am J Orthod. 1958; 44:498-506.

43. Ghafari J, Engel FE, Laster LL. Cephalometric superimposition on the cranial base: a review and a comparison of four methods. Am J Orthod Dentofacial Orthop. 1987; 91:403-13. [PubMed: 3472459]

44. Björk A, Skieller V. Normal and abnormal growth of the mandible. A synthesis of longitudinal cephalomettic implant studies over a period of 25 years. Eur J Orthod. 1983; 5:1-46. [PubMed: 6572593]

45. Park S, Yu H, Kim K, Lee K, Baik H. A proposal for a new analysis of craniofacial morphology by 3-dimensional computed tomography. Am J Orthod Dentofacial Orthop. 2006; 129:600, e23-34. [PubMed: 16679198]

46. Periago DR, Scarfe WC, Moshiri M, Scheetz JP, Silveira AM, Farman AG. Linear accuracy and reliability of cone beam CT derived 3-dimensional images constructed using an orthodontic volumetric rendering program. Angle Orthod. 2008; 78:387-95. [PubMed: 18416632]

47. Wigal TG, Dischinger T, Martin C, Razmus T, Gunel E, Ngan P. Stability of Class II treatment with an edgewise crowned Herbst appliance in the early mixed dentition: skeletal and dental changes. Am J Orthod Dentofacial Orthop. 2011; 140:210-23. [PubMed: 21803259]

48. Valant JR, Sinclair PM. Treatment effects of the Herbst appliance. Am J Orthod Dentofacial Orthop. 1989; 95:138-47. [PubMed: 2916470]

49. McNamara JA Jr. Neuromuscular and skeletal adaptations to altered function in the orofacial region. Am J Orthod. 1973; 64:578-606. [PubMed: 4210182]

50. Buschang PH, Santos-Pinto A. Condylar growth and glenoid fossa displacement during childhood and adolescence. Am J Orthod Dentofacial Orthop. 1998; 113:437-42. [PubMed: 9563360] 
51. Ruf S, Pancherz H. Does bite-jumping damage the TMJ? A prospective longitudinal clinical and MRI study of Herbst patients. Angle Orthod. 2000; 70:183-99. [PubMed: 10926428]

52. Ruf S, Pancherz H. Orthognathic surgery and dentofacial orthopedics in adult Class II Division 1 treatment: mandibular sagittal split osteotomy versus Herbst appliance. Am J Orthod Dentofacial Orthop. 2004; 126:140-52. [PubMed: 15316468]

53. Buschang PH, Gandini LG Junior. Mandibular skeletal growth and modelling between 10 and 15 years of age. Eur J Orthod. 2002; 24:69-79. [PubMed: 11887381]

54. Buschang P, Tanguay R, Demirjian A, LaPalme L, Turkewicz J. Mathematical models of longitudinal mandibular growth for children with normal and untreated Class I division 1 malocclusion. Eur J Orthod. 1988; 10:227-34. [PubMed: 3181302]

55. Baccetti T, Franchi L, McNamara JA Jr, Tollaro I. Early dentofacial features of Class II malocclusion: a longitudinal study from the deciduous through the mixed dentition. Am J Orthod Dentofacial Orthop. 1997; 111:502-9. [PubMed: 9155809]

56. Pancherz H, Stickel A. Position changes of mandibular condyle in Herbst treatment. Radiographic study. Inf Orthod Kieferorthop. 1989; 21:515-27. [PubMed: 2636216]

57. Hansen K, Pancherz H. Long-term effects of Herbst treatment in relation to normal growth development: a cephalometric study. Eur J Orthod. 1992; 14:285-95. [PubMed: 1516661]

58. Nelson B, Hägg U, Hansen K, Bendeus M. A long-term follow-up study of Class II malocclusion correction after treatment with Class II elastics or fixed functional appliances. Am J Orthod Dentofacial Orthop. 2007; 132:499-503. [PubMed: 17920503]

59. Ruf S. Short- and long-term effects of the Herbst appliance on temporomandibular joint function. Semin Orthod. 2003; 9:74-86. 


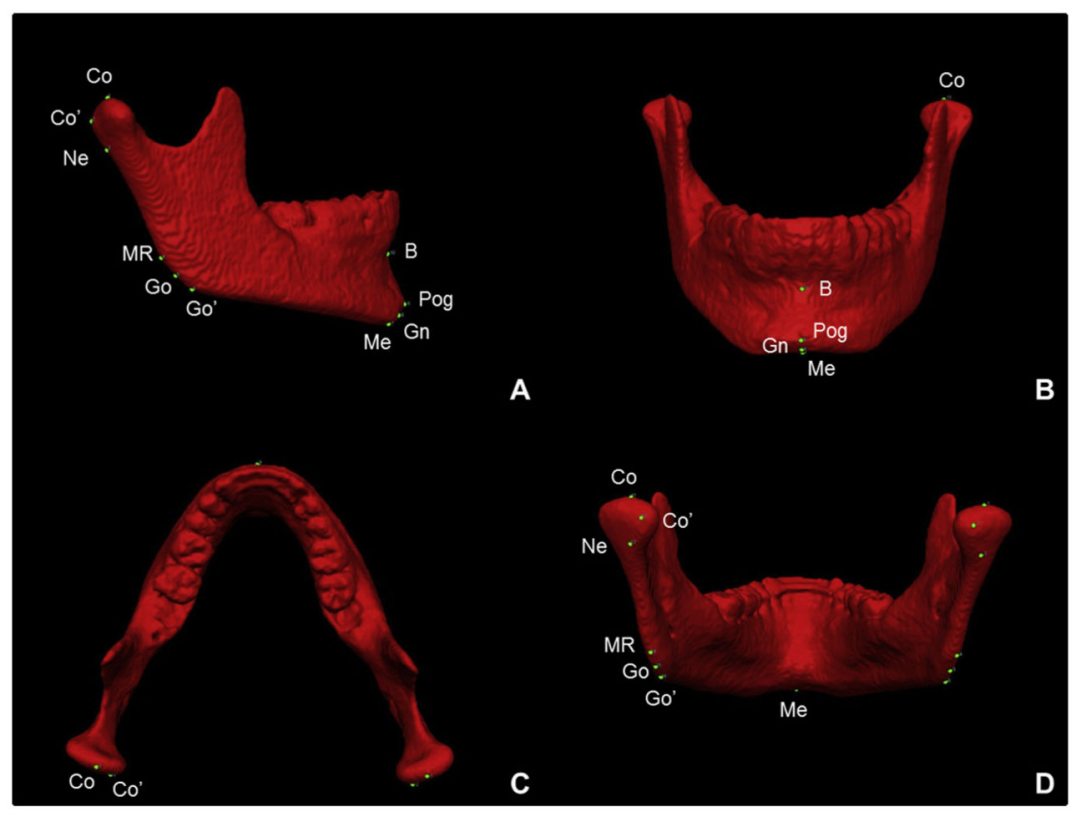

Fig 1.

Three-dimensional mandibular landmark identification: A, sagittal; B, frontal; C, axial; and D, posterior views. 


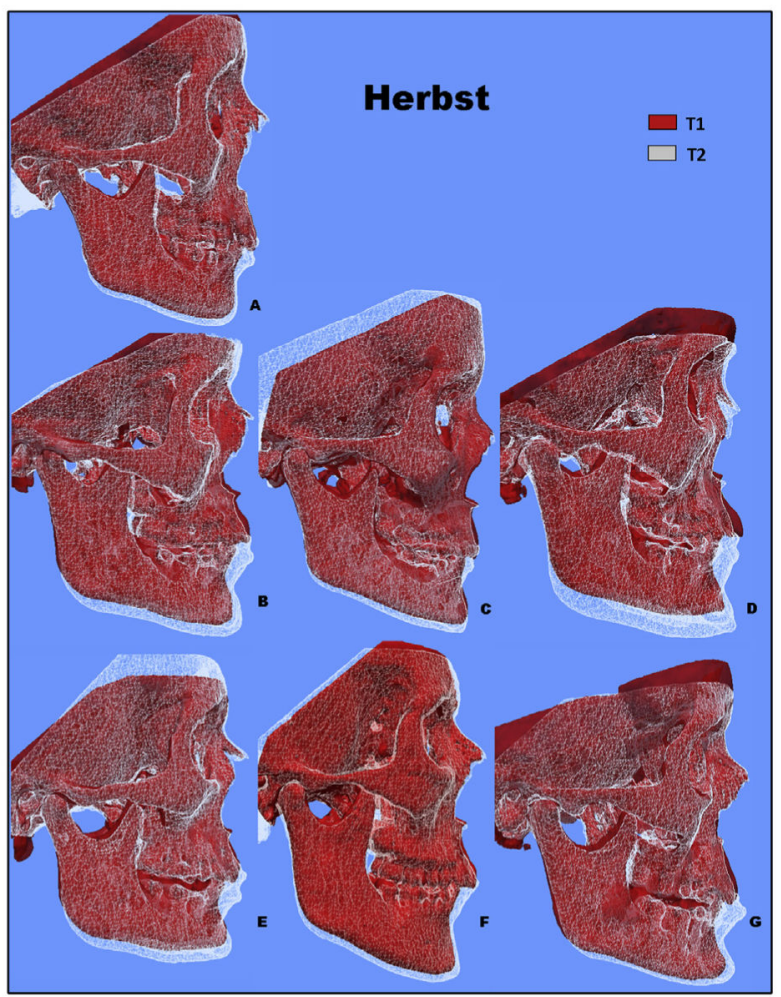

Fig 2.

Herbst subjects' semitransparency of T1 (red) and T2 (white) superimposed 3D renderings registered at the anterior cranial base. 


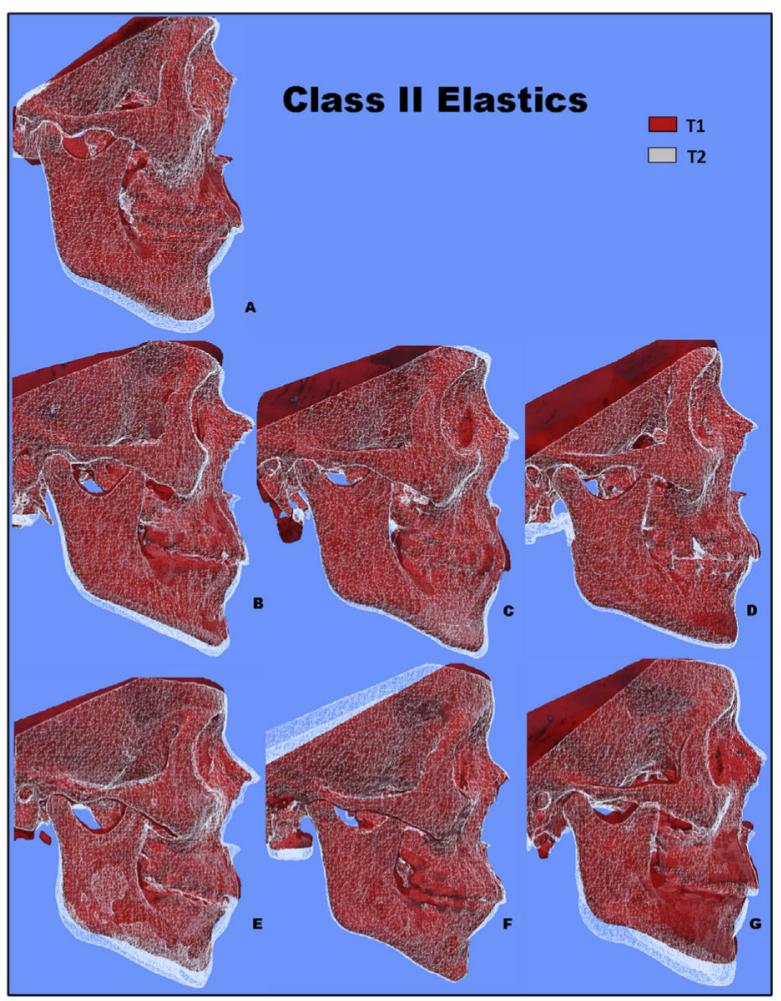

Fig 3.

Class II control subjects' semitransparency of T1 (red) and T2 (white) superimposed 3D renderings registered at the anterior cranial base. 


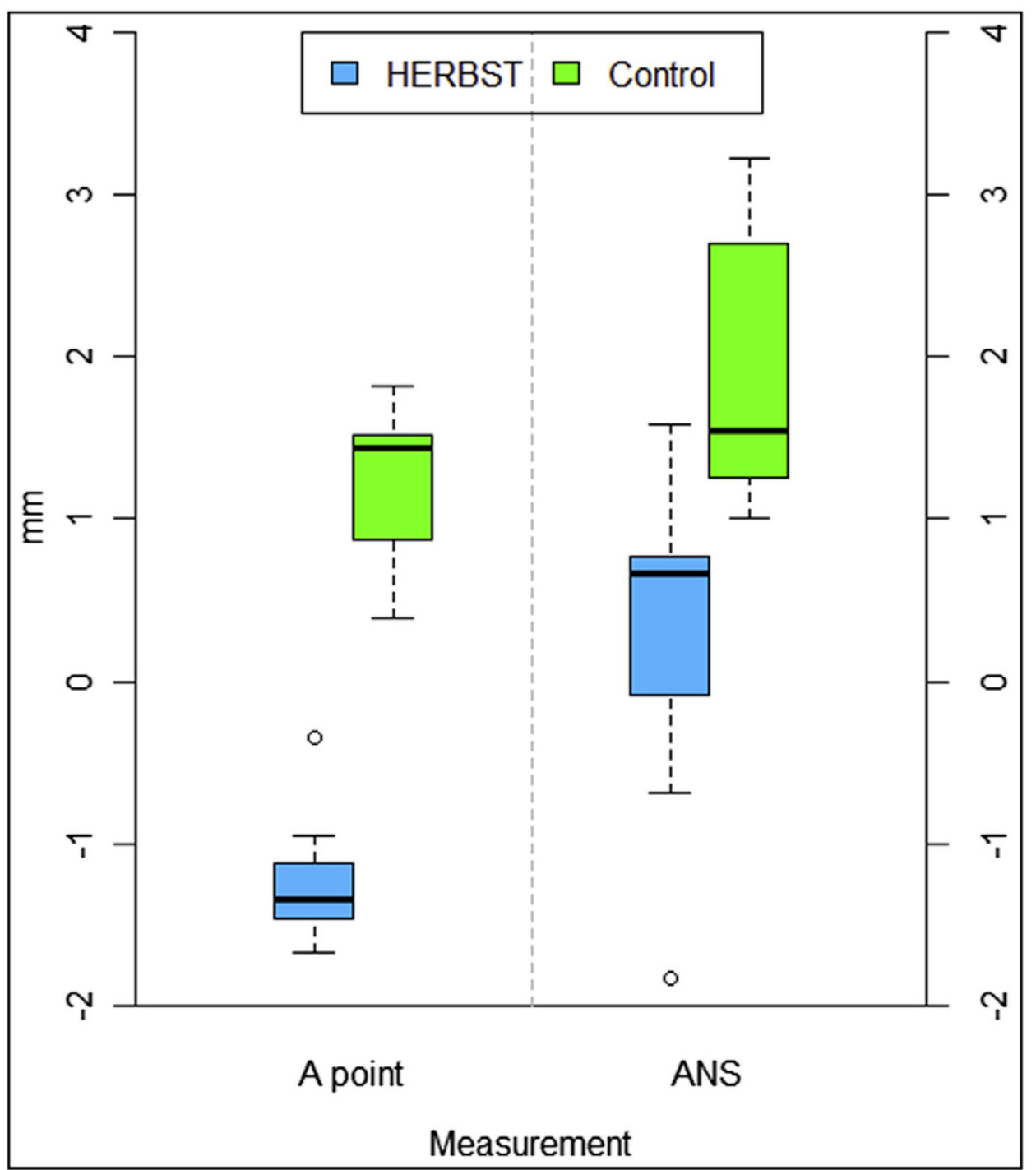

Fig 4.

Box plots of maxillary skeletal changes for the Herbst and control subjects. 


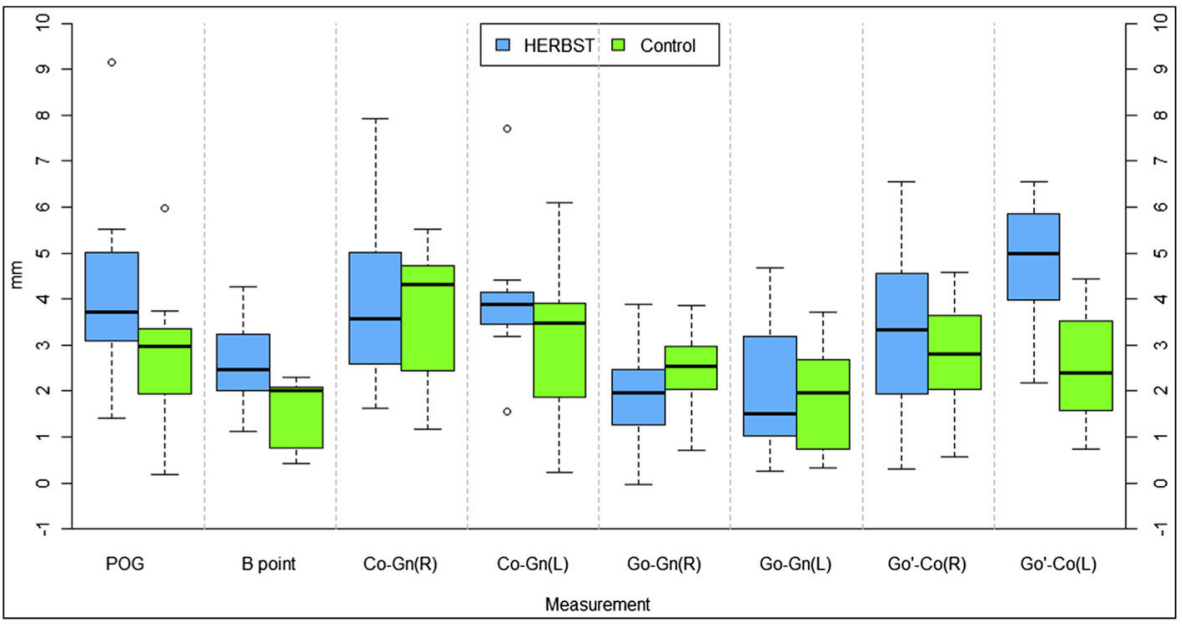

Fig 5.

Box plots of mandibular skeletal changes for the Herbst and control subjects. 


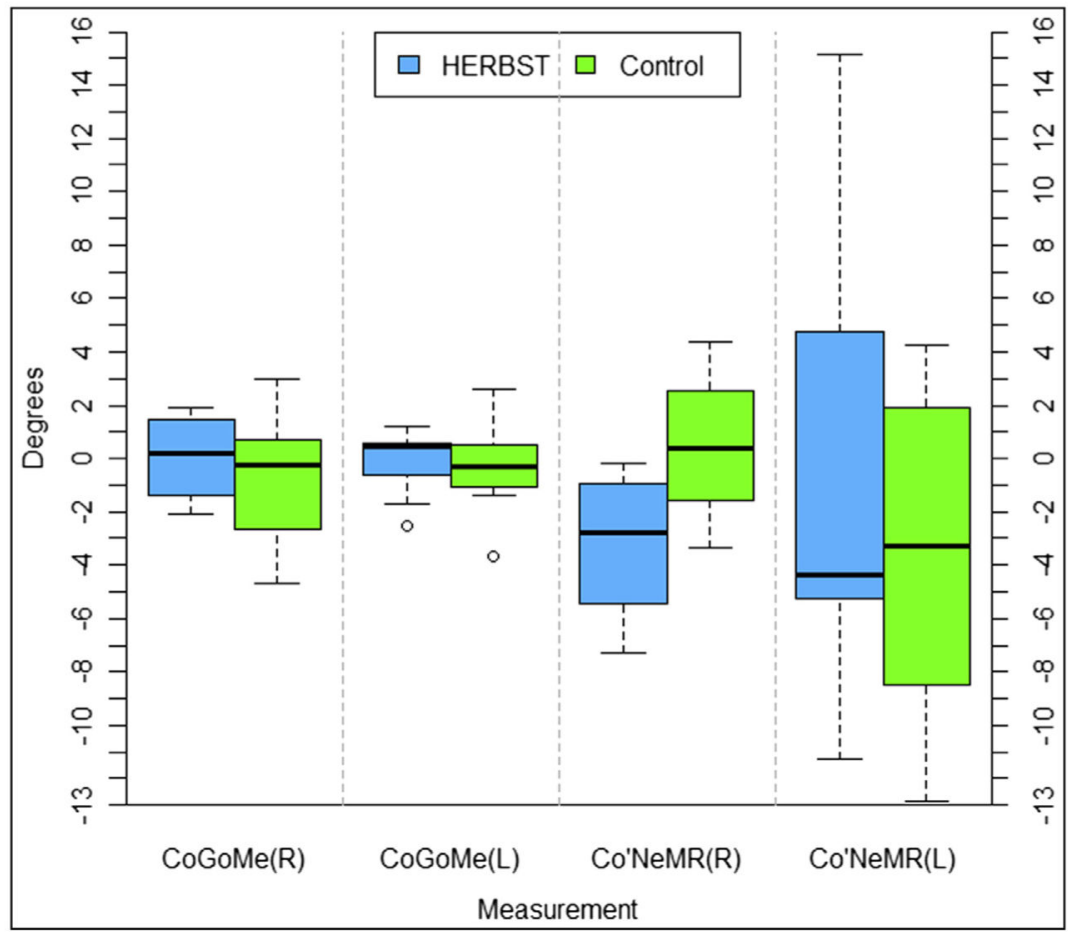

Fig 6.

Box plots showing changes in gonial angle and condylar flexure for the Herbst and control subjects. 


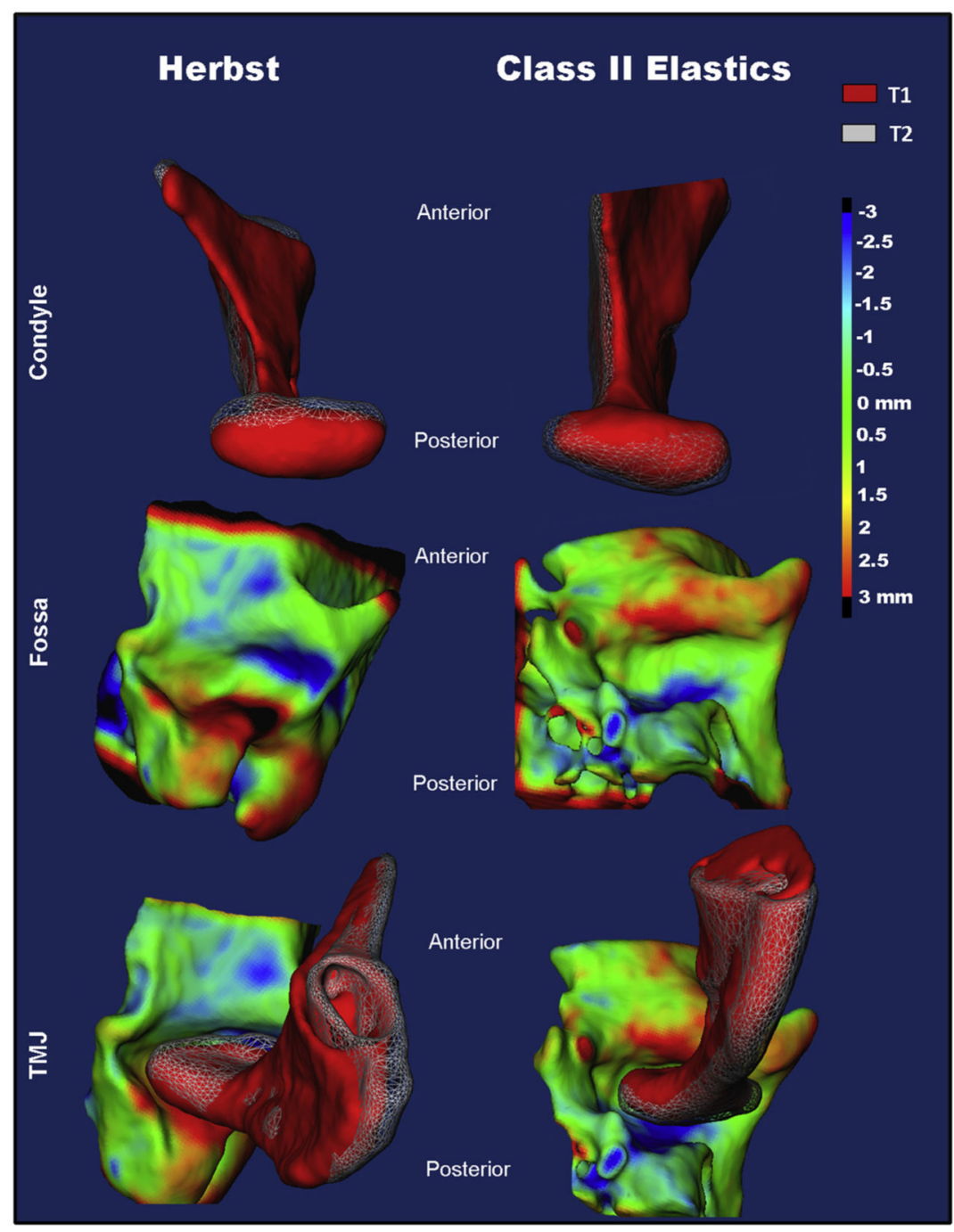

Fig 7.

Condyle, fossa, and temporomandibular changes: condyle semitransparencies of the left condyle for a Herbst subject and a control subject from the sagittal and axial views. Three-dimensional volumes at T1 (red) and T2 (white mesh) were registered at the anterior cranial base. Left condyles were isolated from adjacent structures for improved viewing. The color map shows the glenoid fossa skeletal changes. T1 and T2 superimposed 3D renderings are registered at the anterior cranial base. The fossae are orientated with the anterior aspect near the top of the page and the posterior aspect near the bottom of the page. Color maps are shown with a scale from -3 to $+3 \mathrm{~mm}$. Blue represents regions of bone resorption at $\mathrm{T} 2$ in relation to T1; red represents regions of bone deposition. For the temporomandibular joint (TMJ), a complex view of condyle semitransparency and fossa color maps illustrates the condyle-fossa relationship changes. Class II elastics, Control group. 


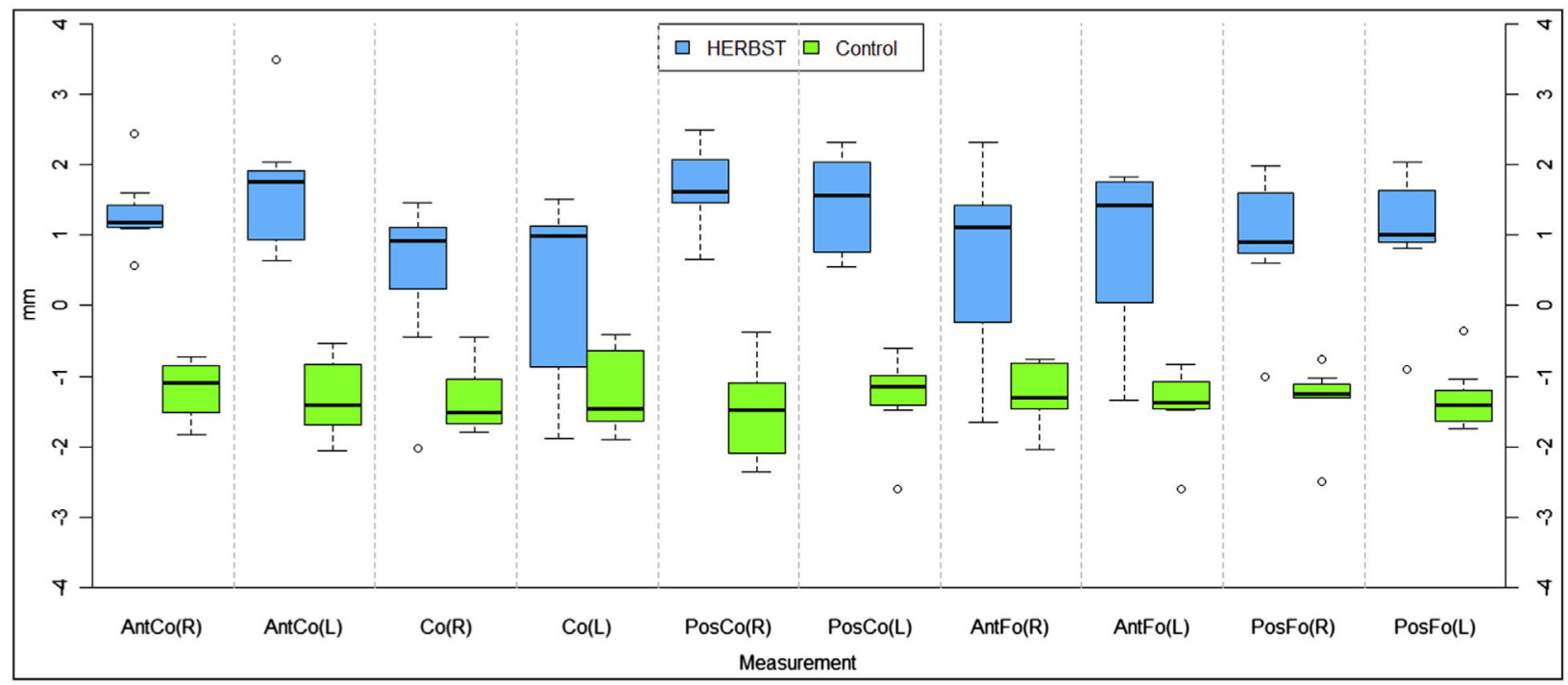

Fig 8.

Box plots showing skeletal changes at the condyle and glenoid fossa for the Herbst and control subjects. 


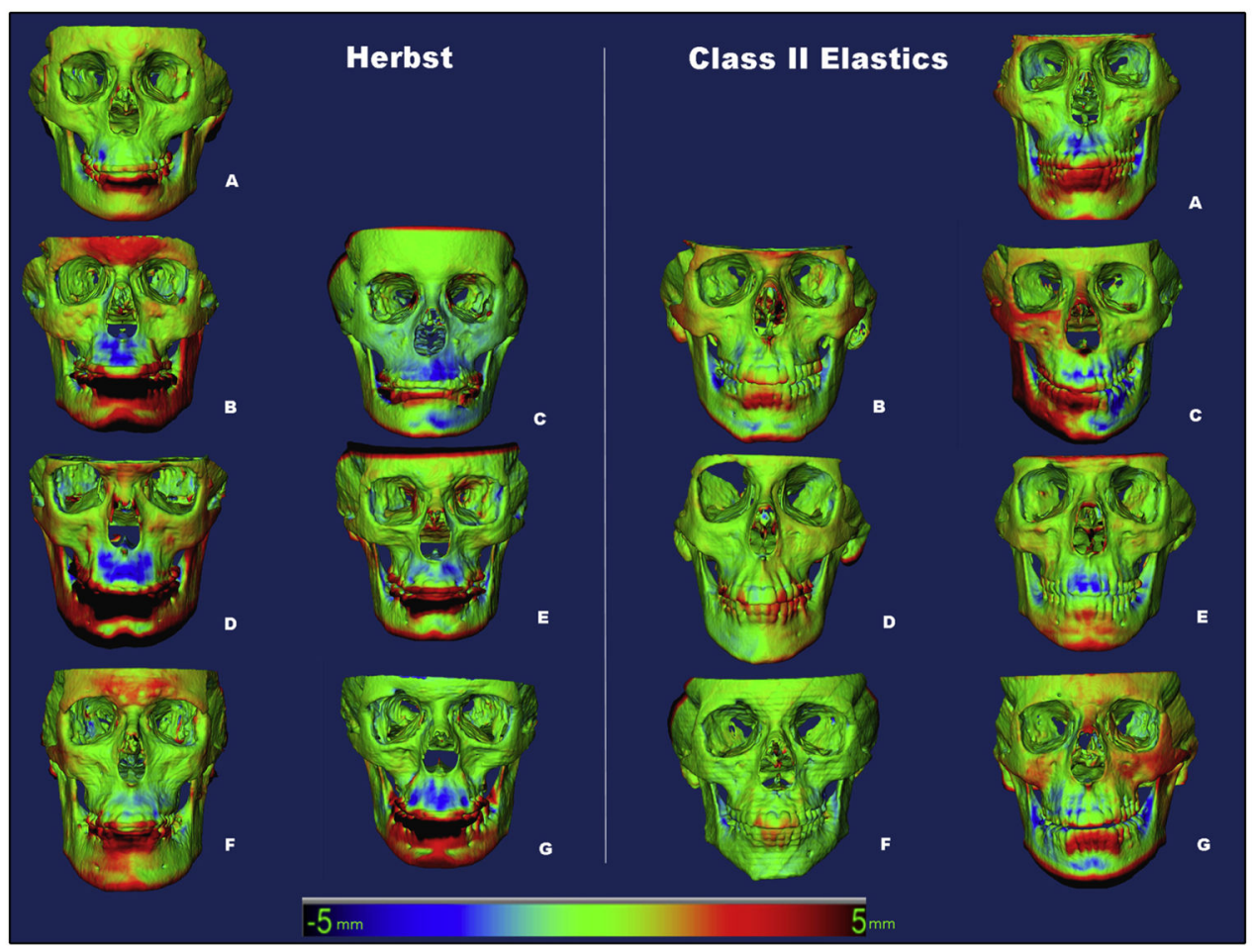

Fig 9.

Color maps showing skeletal displacements calculated from the 3D volume renderings at $\mathrm{T} 2$ in relation to $\mathrm{T} 1$ when registered and superimposed at the anterior cranial base. The color map scale is set from -5 to $+5 \mathrm{~mm}$. Red represents regions of anterior displacement of $\mathrm{T} 2$ in relation to $\mathrm{T} 1$; blue represents regions of posterior displacement. Class II elastics, Control group. 


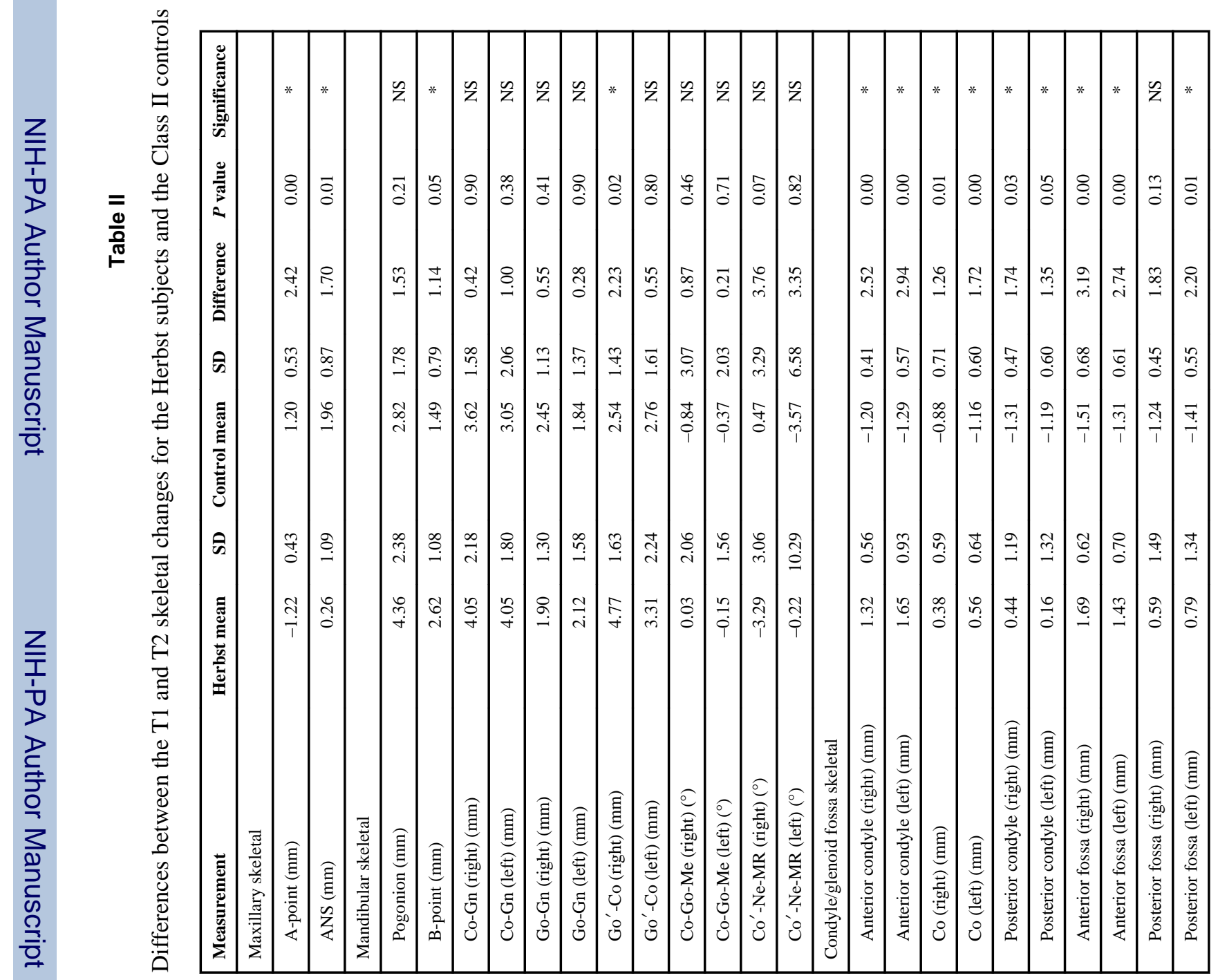


Table III

Intraclass correlation coefficient (ICC) with 95\% CI

\begin{tabular}{|c|c|c|c|}
\hline & ICC & Lower $95 \%$ CI & Upper $95 \%$ CI \\
\hline \multicolumn{4}{|l|}{ Maxillary skeletal } \\
\hline A-point & 0.998 & 0.993 & 0.999 \\
\hline ANS & 0.998 & 0.995 & 1.000 \\
\hline \multicolumn{4}{|l|}{ Mandibular skeletal } \\
\hline Pogonion & 0.997 & 0.990 & 0.999 \\
\hline B-point & 0.972 & 0.916 & 0.991 \\
\hline Co-Gn (right) & 0.911 & 0.748 & 0.971 \\
\hline Co-Gn (left) & 0.963 & 0.890 & 0.988 \\
\hline Go-Gn (right) & 0.962 & 0.912 & 0.983 \\
\hline Go-Gn (left) & 0.950 & 0.904 & 0.976 \\
\hline $\mathrm{Go}^{\prime}-\mathrm{Co}$ (right) & 0.935 & 0.812 & 0.989 \\
\hline Go'-Co (left) & 0.942 & 0.889 & 0.988 \\
\hline Co-Go-Me (right) & 0.972 & 0.948 & 0.980 \\
\hline Co-Go-Me (left) & 0.932 & 0.827 & 0.968 \\
\hline $\mathrm{Co}^{\prime}-\mathrm{Ne}-\mathrm{MR}$ (right) & 0.972 & 0.916 & 0.991 \\
\hline $\mathrm{Co}^{\prime}-\mathrm{Ne}-\mathrm{MR}$ (left) & 0.968 & 0.896 & 0.993 \\
\hline \multicolumn{4}{|c|}{ Condyle/glenoid fossa skeletal } \\
\hline Anterior condyle (right) & 1.000 & 0.998 & 1.000 \\
\hline Anterior condyle (left) & 1.000 & 0.998 & 1.000 \\
\hline Co (right) & 0.989 & 0.965 & 0.996 \\
\hline Co (left) & 0.946 & 0.842 & 0.983 \\
\hline Posterior condyle (right) & 1.000 & 0.999 & 1.000 \\
\hline Posterior condyle (left) & 0.994 & 0.981 & 0.998 \\
\hline Anterior fossa (right) & 0.994 & 0.983 & 0.998 \\
\hline Anterior fossa (left) & 0.997 & 0.990 & 0.999 \\
\hline Posterior fossa (right) & 1.000 & 1.000 & 1.000 \\
\hline Posterior fossa (left) & 1.000 & 0.998 & 1.000 \\
\hline
\end{tabular}

$N e$, Neck of condyle; $M R$, midramus. 